\begin{tabular}{c} 
International Journal of Engineering \& Technology, 7 (3) (2018) 1054-1058 \\
International Journal of Engineering \& Technology \\
SPC \\
Website: $\begin{array}{c}\text { www.sciencepubco.com/index.php/IJET } \\
\text { doi: } 10.14419 / \text { ijet. } 7 \text { 7i3.10023 } \\
\text { Research paper }\end{array}$ \\
\hline
\end{tabular}

\title{
Tea fiber waste as an adsorbent to remove phenol from wastewater
}

\author{
Akash Kumar Surana, Nilesh Bagri, C. R. Girish * \\ Department of Chemical Engineering, Manipal Institute of Technology, Manipal Academy of Higher Education, Manipal- 576104, \\ India \\ *Corresponding author E-mail: girishcr1@ rediffmail.com
}

\begin{abstract}
The current work investigates the phenol adsorption from wastewater using tea fibre waste as an adsorbent. The agricultural waste was treated with phosphoric acid and various properties like surface are, pore volume and average particle size of the adsorbent were determined. The optimization of the parameters like temperature, $\mathrm{pH}$, dosage and concentration were done with response surface methodology (RSM). The quadratic model developed from the optimization was used to relate the variation of percent removal with respect to experimental parameters. The equilibrium data obeyed Freundlich model while kinetic data followed first order model. From the thermodynamic studies, the feasibility of the process was found. The adsorption capacity for the tea fibre was obtained as $12.59 \mathrm{mg} / \mathrm{g}$.
\end{abstract}

Keywords: Tea Fiber Waste; Phenol, Kinetics; Optimization; Adsorption Capacity

\section{Introduction}

The usage of phenol and phenolic compounds are of great importance in different chemical process industries [1]. They generally exists in wastewater released from industries like petroleum refining, distillery, coal gasification, pulp and paper and coke oven industries [2], [3]. Therefore, from the wastewater, phenol enters the aquatic bodies and the water sources in the environment. Phenol is considered as toxic at very low concentration. It reduces the quality of drinking water. It also leads to various health problems such as damage of skin, gastrointestinal and cardiovascular illness [1], [2], [3]. Thus removing phenol from the wastewater is required and is a major challenge for the environmentalist from the pollution point of view.A large number of treatment methods like chemical oxidation, biodegradation, ion exchange, adsorption and membrane separation are used for treating phenol [4]. Adsorption using adsorbent is considered as an effective method, since it treats the pollutant to a very low level.

Tea waste fibre which was easily available in tea plantations in $\mathrm{Si}-$ vasagar, Assam was taken as the adsorbent [5].The tea fibre waste is used to the minimal extent, since it cannot be used as firewood or a source as manure. It is rarely used for feeding some mountain animals in the Assam region. Therefore the present study focusses on the phenol removal from wastewater using tea fibre waste as an adsorbent. The batch studies were carried to determine the influence of the operating conditions on the adsorption process. The optimization of the parameters were done using response surface methodology.

\section{Materials and methods}

\subsection{Preparation of adsorbent}

The tea fibre waste was washed with water and then dried in sunlight. Then it was dried in an oven at $100^{\circ} \mathrm{C}$ for 1 hour so that all the moisture was removed from the sample. The sample was impregnated with $2 \mathrm{M}$ ortho-phosphoric acid in 1:4 ratio for about 20 minutes. Then the slurry was heated inside muffle surface at $450^{\circ} \mathrm{C}$ for $1.5 \mathrm{~h}$ to allow the formation of pores and also the properties of the adsorbent are improved. The sample was cooled and washed with water to remove excess acid [6].The process of washing was continued so that the $\mathrm{pH}$ reaches seven. [7] Finally the material was subjected to filtration, drying and used for the later experiments.

\subsection{The characterization of the adsorbent}

Using the standard procedure, the proximate analysis of the chemically treated adsorbent was performed [8] to calculate the fixed carbon, volatile matter, moisture and ash content. The average particle size was found using particle size analyzer (CILAS 1064, France).The measurement of surface area and pore volume were done using BET apparatus (Smart Instruments, India). The various functional groups which exists on the surface of the adsorbent were determined using Fourier transform infrared spectroscopy (FTIR) instrument, Shimadzu, Japan.

\subsection{Adsorption experiments}

The studies were conducted in $250 \mathrm{~mL}$ conical flasks having $200 \mathrm{~mL}$ of phenol solution $(100 \mathrm{mg} / \mathrm{L})$ at $125 \mathrm{rpm}$. The equilibrium time of the adsorption was calculated as 8 hours. The phenol concentration was measured using U-V spectrophotometer (Shimadzu, Japan) at $270 \mathrm{~nm}$ wavelength. The effect of operating parameters like $\mathrm{pH}$, temperature, dosage and concentration on the phenol removal was investigated. The values of phenol concentration were considered in the range 40 to $100 \mathrm{mg} / \mathrm{L}$ based on the concentration of pollutants in the industrial wastewater [9]. The optimization of the conditions were done using RSM. The values of dosage, $\mathrm{pH}$ and temperature used in the experiments were taken from the literature available 
with respect to similar agricultural materials [10], [11].It is a statistical tool used for determining the optimal conditions and the model equation from the given experimental data [12]. A general RSM technique like central composite design was employed for finding the effect of experimental parameters on percent removal. The present work studies the influence of four independent parameters $\mathrm{pH}$, temperature, dosage and concentration at five coded levels (Table1).The isotherm experiments were conducted at six different concentration values of $40 \mathrm{mg} / \mathrm{L}$ to $140 \mathrm{mg} / \mathrm{L}$. The kinetic studies were performed at the optimal values. The number of experiments were obtained from central composite design for four variables, its higher and lower range and by considering the star points, factorial points and center points [13]. The total design matrix with the experiments conducted and the percent removal results are given in Table 2.

Table 1: Independent Parameters and its level

\begin{tabular}{|c|c|c|c|c|c|c|}
\hline \multirow{2}{*}{ Independent parameters } & \multirow[t]{2}{*}{ Symbol } & \multicolumn{5}{|c|}{ Range and level } \\
\hline & & $-\alpha$ & -1 & 0 & +1 & $+\alpha$ \\
\hline $\mathrm{pH}$ & $\mathrm{X}_{1}$ & 2 & 4 & 6 & 8 & 10 \\
\hline Temperature $\left({ }^{\circ} \mathrm{C}\right)$ & $\mathrm{X}_{2}$ & 20 & 30 & 40 & 50 & 60 \\
\hline Dosage $(g)$ & $\mathrm{X}_{3}$ & 0.2 & 0.8 & 1.4 & 2.0 & 2.6 \\
\hline Concentration (mg/L) & $\mathrm{X}_{4}$ & 10 & 40 & 70 & 100 & 130 \\
\hline
\end{tabular}

Table 2: Design Matrix for the Experimental Parameters and Results Obtained

\begin{tabular}{|c|c|c|c|c|c|c|c|c|c|}
\hline \multirow[t]{2}{*}{ Expt No: } & \multicolumn{4}{|c|}{ Coded parameters } & \multicolumn{5}{|c|}{ Actual parameters } \\
\hline & $x_{1}$ & $x_{2}$ & $x_{3}$ & $x_{4}$ & $\mathrm{pH}$ & Temperature $\left({ }^{\circ} \mathrm{C}\right)$ & Dosage $(\mathrm{g})$ & Concentration (mg/L) & \%rem \\
\hline 1 & -1 & -1 & -1 & -1 & 4 & 30 & 0.8 & 40 & 46.25 \\
\hline 2 & 1 & -1 & -1 & -1 & 8 & 30 & 0.8 & 40 & 53.75 \\
\hline 3 & -1 & 1 & -1 & -1 & 4 & 50 & 0.8 & 40 & 33.75 \\
\hline 4 & 1 & 1 & -1 & -1 & 8 & 50 & 0.8 & 40 & 42.5 \\
\hline 5 & -1 & -1 & 1 & -1 & 4 & 30 & 2 & 40 & 70 \\
\hline 6 & 1 & -1 & 1 & -1 & 8 & 30 & 2 & 40 & 68.75 \\
\hline 7 & -1 & 1 & 1 & -1 & 4 & 50 & 2 & 40 & 76.25 \\
\hline 8 & 1 & 1 & 1 & -1 & 8 & 50 & 2 & 40 & 77.5 \\
\hline 9 & -1 & -1 & -1 & 1 & 4 & 30 & 0.8 & 100 & 39 \\
\hline 10 & 1 & -1 & -1 & 1 & 8 & 30 & 0.8 & 100 & 37.5 \\
\hline 11 & -1 & 1 & -1 & 1 & 4 & 50 & 0.8 & 100 & 33 \\
\hline 12 & 1 & 1 & -1 & 1 & 8 & 50 & 0.8 & 100 & 37.5 \\
\hline 13 & -1 & -1 & 1 & 1 & 4 & 30 & 2 & 100 & 61 \\
\hline 14 & 1 & -1 & 1 & 1 & 8 & 30 & 2 & 100 & 64 \\
\hline 15 & -1 & 1 & 1 & 1 & 4 & 50 & 2 & 100 & 67 \\
\hline 16 & 1 & 1 & 1 & 1 & 8 & 50 & 2 & 100 & 67.5 \\
\hline 17 & -2 & 0 & 0 & 0 & 2 & 40 & 1.4 & 70 & 63.5 \\
\hline 18 & 2 & 0 & 0 & 0 & 10 & 40 & 1.4 & 70 & 64.3 \\
\hline 19 & 0 & -2 & 0 & 0 & 6 & 20 & 1.4 & 70 & 77.1 \\
\hline 20 & 0 & 2 & 0 & 0 & 6 & 60 & 1.4 & 70 & 62.8 \\
\hline 21 & 0 & 0 & -2 & 0 & 6 & 40 & 0.2 & 70 & 11.4 \\
\hline 22 & 0 & 0 & 2 & 0 & 6 & 40 & 2.6 & 70 & 88.6 \\
\hline 23 & 0 & 0 & 0 & -2 & 6 & 40 & 1.4 & 10 & 95 \\
\hline 24 & 0 & 0 & 0 & 2 & 6 & 40 & 1.4 & 130 & 60.8 \\
\hline 25 & 0 & 0 & 0 & 0 & 6 & 40 & 1.4 & 70 & 70 \\
\hline 26 & 0 & 0 & 0 & 0 & 6 & 40 & 1.4 & 70 & 70 \\
\hline 27 & 0 & 0 & 0 & 0 & 6 & 40 & 1.4 & 70 & 69.3 \\
\hline 28 & 0 & 0 & 0 & 0 & 6 & 40 & 1.4 & 70 & 70 \\
\hline 29 & 0 & 0 & 0 & 0 & 6 & 40 & 1.4 & 70 & 71.4 \\
\hline 30 & 0 & 0 & 0 & 0 & 6 & 40 & 1.4 & 70 & 70 \\
\hline
\end{tabular}

\section{Results and discussions}

\subsection{Characterization of the adsorbent}

The proximate analysis of the chemically treated sample is given in table 3. It represents that the material possesses higher fixed carbon content and it shows that the material has good adsorption capacity for the pollutant [14]. The pore volume and surface area of the material were determined as $1.3021 \mathrm{~cm}^{3} / \mathrm{g}$ and $1235.91 \mathrm{~m}^{2} / \mathrm{g}$ respectively showing the potential of the adsorbent to adsorb phenol [15]. The average particle size was $54.80 \mu \mathrm{m}$ which improves the surface area and thus the efficiency of the adsorbent.

The FTIR spectrum of the chemically treated sample shows broad adsorption peak at $3490.92 \mathrm{~cm}^{-1}$ that corresponds to overlapping of $-\mathrm{OH}$ and $-\mathrm{NH}$ groups [16]. The peak found at $2356.85 \mathrm{~cm}^{-1}$ and $1623.95 \mathrm{~cm}^{-1}$ corresponding to the $C \equiv N$ group and the $C=C$ group [17]. The peak formed at $1569.95 \mathrm{~cm}^{-1}$ and $1434.94 \mathrm{~cm}^{-1} \mathrm{de}-$ picts the $-\mathrm{NO}_{2}$ group and the $\mathrm{C}-\mathrm{H}$ group with alkyl halides respectively. From these results, it can be inferred that these bonds are responsible for adsorption of phenol onto the chemically treated carbon and are shown in figure 1. 
Table 3: Proximate Analysis of the Treated Adsorbent

\begin{tabular}{lllll}
\hline S1. No & Parameter & Percentage & Sl.No & Parameter \\
\hline 1 & Moisture & 8.5 & 2 & Psh content \\
3 & Volatile matter & 28.5 & 4 & Fixed carbon content \\
\hline
\end{tabular}

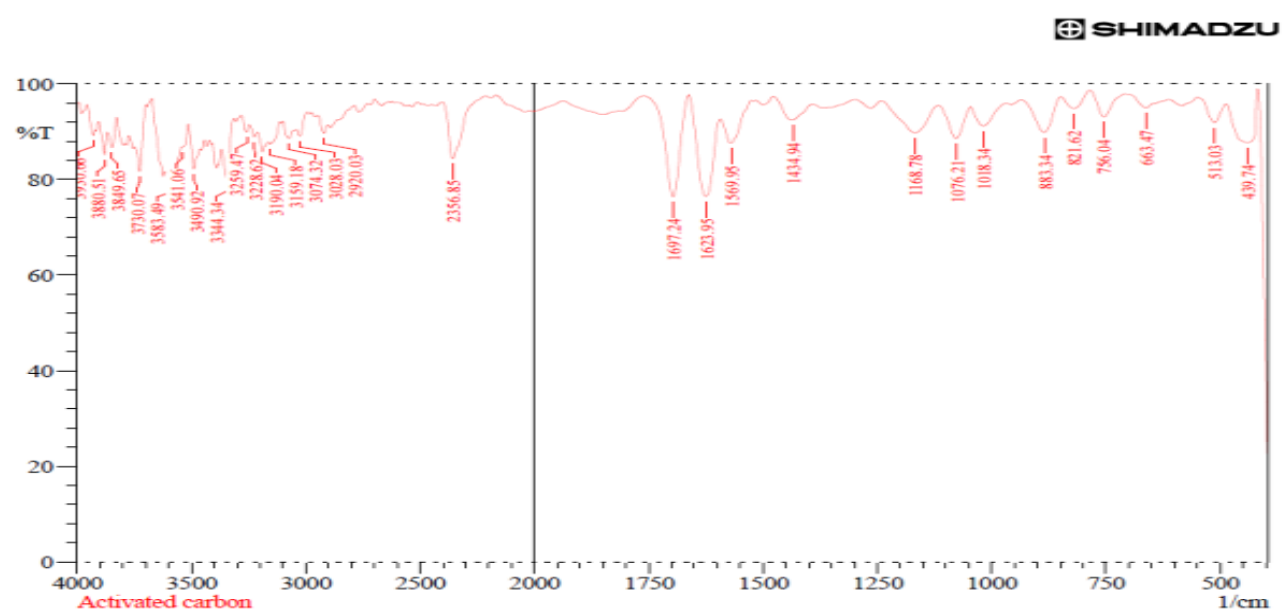

Fig. 1: The FTIR Spectra of the Treated Adsorbent.

\subsection{Development of model equation and optimization of experimental parameters}

The design matrix having response values i.e. percentage removal calculated from the experiments are given in table 1. The percentage removal values obtained from the range of experiments varied from $11.4 \%$ to $95 \%$. A quadratic polynomial equation was obtained which shows the interaction between the variables and is also helpful to optimize the parameters [18], [19]. The model equation for percentage removal in terms of coded factors by neglecting all the insignificant factors is given as

$$
\% \text { rem }=68.44+15.96 x_{3}-5.44 x_{4}-3.13 x_{1}^{2}-6.61 x_{3}^{2}
$$

The value of correlation coefficient $\left(R^{2}\right)$ and standard deviation was employed for checking the validity of the model [20]. The $R^{2}$ value for the equation was obtained as 0.8566 and this implies that $85.66 \%$ of the result obtained was because of the variation in the experimental conditions [13], [21], [22]. Also it shows that $14.34 \%$ of the variation is not discussed by the model and is due to residual errors [21]. The model can be validated if the value of $R^{2}$ is approaching unity and value of standard deviation is lower [23]. The standard deviation was obtained as 7.43, showing good fit with the model. The value of coefficient of variance 12.25 shows better precision of the experimental data [22]. The optimal experimental conditions were obtained as $40 \mathrm{mg} / \mathrm{L}$ of concentration, $2 \mathrm{~g}$ of dosage, temperature of $43.4^{\circ} \mathrm{C}, \mathrm{pH}$ of 6.2 and percent removal of $85.54 \%$. The verification experiments were conducted at these optimum conditions and the error was obtained as $0.63 \%$.

\subsection{Isotherm studies}

Several models have been reported in literature to explain the equilibrium relationships between adsorbent and the adsorbate. The most common models like Langmuir, Freundlich and Temkin models are discussed below.

The Langmuir isotherm is explained assuming that adsorption is occurring uniformly on the surface. The simplified form of the model is represented as [24]

$\frac{C_{e}}{q_{e}}=\frac{C_{e}}{q_{m}}+\frac{1}{k_{L} q_{m x}}$

$q_{e}$ and $C_{e}$ the adsorption capacity $(\mathrm{mg} / \mathrm{g}$ ) and solute concentration $(\mathrm{mg} / \mathrm{L})$ at equilibrium respectively, $k_{L}$ the model constant $(\mathrm{L} / \mathrm{mg})$ and $q_{m x}$ the monolayer adsorption capacity ( $\mathrm{mg} / \mathrm{g}$ ). The parameters $k_{L}$ and $q_{m x}$ are calculated through the linear plot of $C_{e} / q_{e} \mathrm{v} / \mathrm{s}$ $C_{e}$.

Freundlich model is obtained from the concept that adsorption is happening non-uniformly in multilayers.[25, 26] The energy distribution of the process is non-uniform on the solid surface. It is given in the linear form as

$\log q_{e}=\log k_{f}+\frac{1}{n} \log C_{e}$

$n$ In addition, $k_{f}\left(m g^{1-\frac{1}{n}} L^{1 / n} g^{-1}\right)$ are the model constants. The model parameters $k_{f}$ and $n$ are obtained through the linear plot of $\log q_{e} \mathrm{v} / \mathrm{s} \log C_{e}$

The Temkin isotherm describes indirectly how the adsorbent and pollutant molecules interact with each other. It is represented as [11]

$q_{e}=B \ln A+B \ln C_{e}$

$A$ In addition, $B$ are the model parameters? The values of constants are calculated by plotting $q_{e} \mathrm{v} / \mathrm{s} \ln C_{e}$.

The isotherm parameters obtained from the models are represented in Table 4. The model was validated based on the value of regression coefficient and it was observed that the experimental data was fitting best with the Freundlich isotherm. Therefore it describes that the process is physical adsorption and pollutant gets adsorbed on the solid surface in multilayers. The monolayer adsorption capacity was calculated to be $12.59 \mathrm{mg} / \mathrm{g}$.

Table 4: The Model Parameters from Different Isotherm Models.

\begin{tabular}{llll}
\hline Model & \multicolumn{3}{c}{ Isotherm constants } \\
\hline Langmuir & $q_{m x}=12.59 \mathrm{mg} / \mathrm{g}$ & $k_{L}=0.064 \mathrm{~L} / \mathrm{mg}$ & $R^{2}=0.9442$ \\
Freundlich & $k_{f}=1.459\left(\mathrm{mg}^{1-\frac{1}{n}} \mathrm{~L}^{1 / n} \mathrm{~g}^{-1}\right)$ & $n=1.953$ & $R^{2}=0.9838$ \\
Temkin & $A=0.376 \mathrm{~L} / \mathrm{g}$ & $B=8.199 \mathrm{~J} / \mathrm{mol}$ & $R^{2}=0.9383$ \\
\hline
\end{tabular}

\subsection{Thermodynamic studies}

The feasibility of the process was found by performing thermodynamic studies and determining the values of $\Delta G, \Delta H$ and $\Delta S$ from the equations.

$\Delta \mathrm{G}=\Delta \mathrm{H}-\mathrm{T} \Delta \mathrm{S}$

$\Delta \mathrm{G}=-\mathrm{RT} \ln \mathrm{K}_{\mathrm{d}}$ 
$\mathrm{K}_{\mathrm{d}}=\frac{\mathrm{q}_{\mathrm{e}}}{\mathrm{C}_{\mathrm{e}}}$

$\ln \mathrm{K}_{\mathrm{d}}=\frac{\Delta \mathrm{S}}{\mathrm{R}}-\frac{\Delta \mathrm{H}}{\mathrm{RT}}$

where $\Delta \mathrm{G}, \Delta \mathrm{H}$ and $\Delta \mathrm{S}$ are changes in Gibbs free energy, enthalpy, and entropy respectively. The parameters $\Delta \mathrm{H}$ and $\Delta \mathrm{S}$ are determined through the plot of $\ln K_{d}$ v/s $1 / \mathrm{T}$ and are shown in Table 5 .

Table 5: The Values of Calculated Thermodynamic Parameters at Differen Temperatures.

\begin{tabular}{llllll}
\hline \multirow{2}{*}{ Parameter } & $\begin{array}{l}\Delta \mathrm{G}(\mathrm{kJ} / \mathrm{mol}) \\
293 \mathrm{~K}\end{array}$ & $\begin{array}{l}\Delta \mathrm{G}(\mathrm{kJ} / \mathrm{mol}) \\
313 \mathrm{~K}\end{array}$ & $\begin{array}{l}\Delta \mathrm{G}(\mathrm{kJ} / \mathrm{mol}) \\
333 \mathrm{~K}\end{array}$ & $\begin{array}{l}\Delta \mathrm{S} \\
(\mathrm{J} / \mathrm{mol} \mathrm{K})\end{array}$ & $\begin{array}{l}\Delta \mathrm{H} \\
(\mathrm{kJ} / \mathrm{mol})\end{array}$ \\
\hline-2.6762 & -2.2049 & -1.2384 & -35.4184 & -13.1261 \\
\hline
\end{tabular}

The $\Delta \mathrm{G}$ values shows that the reaction is feasible and spontaneous at the temperatures. The negative value of $\Delta \mathrm{S}$ and $\Delta$ Himplies that randomness reduces at solid liquid interface and process is exothermic in nature [27], [28].

\subsection{Kinetic studies}

Kinetic studies monitors the experimental parameters that affect the speed of the reaction. The different aspects like the mechanism, how the adsorbent- pollutant complex formed and how the interaction takes place can be understood from kinetic studies [29]. It helps in evaluating the residence time required for the solute in the adsorbent solution medium [30].

Pseudo-first-order kinetic model

The model is derived by assuming reversible physical adsorption The model is represented in the form [31], [32]

$$
\log \left(q_{e}-q_{t}\right)=\log q_{e}-\frac{k_{f s}}{2.303} t
$$

Where $\mathrm{q}_{\mathrm{t}}$ is the capacity at any time $\mathrm{t}(\mathrm{mg} / \mathrm{g}), \mathrm{k}_{\mathrm{fs}}$ the model rate constant $\left(\mathrm{min}^{-1}\right)$. The values of constants $\mathrm{k}_{\mathrm{fs}}$ and $\mathrm{q}_{\mathrm{e}}$ are evaluated through the plot of $\log \left(\mathrm{q}_{\mathrm{e}}-\mathrm{q}_{\mathrm{t}}\right) \mathrm{v} / \mathrm{s} \mathrm{t}$.

Pseudo-second-order kinetic model

The model is generally applicable to the systems where chemisorption is the slowest step. The model is written in the simplified form as [31], [33]

$\frac{\mathrm{t}}{\mathrm{q}_{\mathrm{t}}}=\frac{1}{\mathrm{k}_{\mathrm{s}} \mathrm{q}_{\mathrm{e}}^{2}}+\frac{1}{\mathrm{q}_{\mathrm{e}}} \mathrm{t}$

where $\mathrm{k}_{\mathrm{s}}$ the second-order rate constant $(\mathrm{g} / \mathrm{mg} \min )$. The model constants are obtained through the plot oft $/ \mathrm{q}_{\mathrm{t}} \mathrm{v} / \mathrm{s} \mathrm{t}$.

Intra-particle diffusion model

In the case of porous particles, particle diffusion may be taken as the slowest step. The rate equation can be given as [34]

$$
\mathrm{q}_{\mathrm{t}}=\mathrm{k}_{\mathrm{p}} \mathrm{t}^{0.5}+\mathrm{I}
$$

$\mathrm{k}_{\mathrm{p}}$ is the model rate constant $\left(\frac{\mathrm{mg}}{\mathrm{gmin}^{0.5}}\right)$, Ithe boundary layer thickness. The model is generally applied if the plot of $\mathrm{q}_{\mathrm{t}} \mathrm{v} / \mathrm{s} \mathrm{t}^{0.5}$ is passing through the origin.

The kinetic constants evaluated from the models are given in Table 6 . The value of regression coefficient was used to validate the model. It was found that higher $\mathrm{R}^{2}$ value was obtained for pseudo first order model in comparison with other models. The experimental adsorption capacity of $4.25 \mathrm{mg} / \mathrm{g}$ was matching closely with the calculated value of first order model. Therefore it explains that physisorption is happening on the surface of the adsorbent.

\begin{tabular}{|c|c|c|c|c|c|c|c|c|}
\hline \multicolumn{3}{|c|}{$\begin{array}{l}\text { Pseudo-first order } \\
\text { model }\end{array}$} & \multicolumn{3}{|c|}{$\begin{array}{l}\text { Pseudo-second order } \\
\text { model }\end{array}$} & \multicolumn{3}{|c|}{ Intraparticle diffusion } \\
\hline $\begin{array}{l}\mathrm{k}_{\mathrm{fs}}, \\
\mathrm{min}^{-1}\end{array}$ & $\begin{array}{l}\left(\mathrm{q}_{\mathrm{e}}\right)_{\text {cal }} \\
\mathrm{mg} / \mathrm{g}\end{array}$ & $\mathrm{R}^{2}$ & $\begin{array}{l}k_{\mathrm{s}}, \\
\mathrm{g} / \mathrm{mg} \min \end{array}$ & $\begin{array}{l}\left(\mathrm{q}_{\mathrm{e}}\right)_{\text {cal }}, \\
\mathrm{mg} / \mathrm{g}\end{array}$ & $\mathrm{R}^{2}$ & $\begin{array}{l}\mathrm{k}_{\mathrm{p},} \\
\left(\frac{\mathrm{mg}}{\mathrm{g}} \min ^{0.5}\right)\end{array}$ & I & $\mathrm{R}^{2}$ \\
\hline 0.01197 & 5.631 & 0.9863 & 0.00239 & 5.909 & 0.9783 & 0.2056 & 0.2911 & 0.9082 \\
\hline
\end{tabular}

Table 6: The Constants Calculated from the Kinetic Models

\section{Conclusion}

The current study proved the capability of the tea fibre waste as an effective adsorbent to remove phenol from wastewater. The adsorbent treated with phosphoric acid showed improvement in property which was beneficial for the adsorption process. The optimum conditions from the RSM were obtained as concentration of $40 \mathrm{mg} / \mathrm{L}$, $2 \mathrm{~g}$ of dosage, temperature of $43.4^{\circ} \mathrm{C}, \mathrm{pH}$ of 6.2 and percent removal of $85.54 \%$.The isotherm data obeyed Freundlich model and the kinetic data followed pseudo first order model showing that physical adsorption is the possible process. The thermodynamic studies implied that the process is feasible and spontaneous. The monolayer adsorption capacity for the tea fibre waste was calculated as 12.59 $\mathrm{mg} / \mathrm{g}$.

\section{Acknowledgements}

The authors are thankful to the Chemical Engineering Department, MIT, Manipal for providing the facilities to carry out the research work.

\section{References}

[1] Hank, D., Saidani, N., Namane, A., Hellal, A. (2010), Batch phenol biodegradation study and application of factorial experimental design, Journal of Engineering Science \& Technology Review, 3(1), 123-127.

[2] Amara, A.A.A.F., Salem, S.R. (2010), Logical and experimental design for phenol degradation using immobilized Acinetobacter sp. Culture, IIUM Engineering Journal, 11(1), 89-104.

[3] Chakraborty, S., Bhattacharya, T., Patel, T.N., Tiwari, K.K. (2010), Biodegradation of phenol by native microorganisms isolated from coke processing wastewater, Journal of Environmental Biology, 31 , 293-296.

[4] Kumar, A., Kumar, S., Kumar, S. (2003), Adsorption of resorcinol and catechol on granular activated carbon: equilibrium and kinetics, Carbon, 41(15), 3015-3025 https://doi.org/10.1016/S00086223(03)00431-7.

[5] Girish, C.R., Singh, P., Goyal, A.K. (2017), Removal of Phenol from Wastewater Using tea waste and optimization of conditions using response surface methodology, International Journal of Applied Engineering Research, 12(13), 3857-3863.

[6] Rengaraj, S., Arabindoo, B., Murugesan, V. (1999), Preparation and characterisation of activated carbon from agricultural wastes, Indian Journal of Chemical Technology, 6, 1-4.

[7] Moreno-Castilla, C. (2004), Adsorption of organic molecules from aqueous solutions on carbon materials, Carbon, 42 (1), 83-94 https://doi.org/10.1016/i.carbon.2003.09.022.

[8] APHA, Standard Methods for the Examination of Water and Wastewater, (1989), American Water Works Association, New York, NY, USA, 17th edition.

[9] Ucun, H., Yildiz, E., Nuhoglu, A. (2010), Phenol biodegradation in a batch jet loop bioreactor (JLB): kinetics study and $\mathrm{pH}$ variation, Bioresource Technology, 101(9), 2965-2971 https://doi.org/10.1016/j.biortech.2009.12.005.

[10] Rengaraj, S., Moon, S., Sivabalan, R., Arabindoo, B., Murugesan, V. (2002), Agricultural solid waste for the removal of organics: adsorption of phenol from water and wastewater by palm seed coat activated carbon, Waste Management, 22, 543-548.

[11] Omri, A., Benzina, M. (2012), Removal of manganese (II) ions from aqueous solutions by adsorption on activated carbon derived a new precursor: Ziziphus spina-christi seeds, Alexandria Engineering Journal, 51(4), 343-350 https://doi.org/10.1016/j.aej.2012.06.003.

[12] Zhou, J., Yu, X., Ding, C., Wang, Z., Zhou, Q., Pao, H., Cai, W. (2011), Optimization of phenol degradation by Candida tropicalis Z04 using Plackett-Burman design and response surface methodology, Journal of Environmental Sciences, 23(1), 22-30 https://doi.org/10.1016/S1001-0742(10)60369-5.

[13] Pakravan, P., Akhbari, A., Moradi, H., Azandaryani, A.H., Mansouri, A.M., Safari, M. (2015), Process modeling and evaluation of petroleum refinery wastewater treatment through response surface methodology and artificial neural network in a photocatalytic reactor using poly ethyleneimine $(\mathrm{PEI}) /$ titania $\left(\mathrm{TiO}_{2}\right)$ multilayer film on quartz tube, Applied Petrochemical Research, 5(1), 47-59 https://doi.org/10.1007/s13203-014-0077-7. 
[14] Din, A.T.M., Hameed, B.H., Ahmad, A.L. (2009), Batch adsorption of phenol onto physiochemical-activated coconut shell, Journal of Hazardous Materials, 161(2-3), 1522-1529 https://doi.org/10.1016/j.jhazmat.2008.05.009.

[15] Aygün, A., Yenisoy-Karakaş, S., Duman, I. (2003), Production of granular activated carbon from fruit stones and nutshells and evaluation of their physical, chemical and adsorption properties, Microporous and mesoporous materials, 66(2-3), 189-195 https://doi.org/10.1016/j.micromeso.2003.08.028.

[16] Hameed, B.H., Krishni, R.R., Sata, S.A. (2009), A novel agricultura waste adsorbent for the removal of cationic dye from aqueous solutions, Journal of hazardous materials, 162(1), 305-311 https://doi.org/10.1016/j.jhazmat.2008.05.036.

[17] Morrison, R.T., Boyd, R.N. (2004), Organic Chemistry, Pearson Education, Singapore, 6 th edition

[18] Alkhatib, M.F., Mamun, A.A., Akbar, I. (2015), Application of response surface methodology (RSM) for optimization of color removal from POME by granular activated carbon, International journal of environmental science and technology, 12(4), 1295-1302.

[19] Zarei, M., Khataee, A., Fathinia, M., Seyyednajafi, F., Ranjbar, H. (2012), Combination of nanophotocatalysis with electro-Fenton-like process in the removal of phenol from aqueous solution: GC analysis and response surface approach, International Journal of Industria Chemistry, 3(1), 27 https://doi.org/10.1186/2228-5547-3-27.

[20] Bhaumik, R., Mondal, N.K., (2016), Optimizing adsorption of fluoride from water by modified banana peel dust using response surface modelling approach, Applied Water Science, 6(2), 115-135 https://doi.org/10.1007/s13201-014-0211-9.

[21] Kaushik, R., Marwah, R.G., Gupta, P., Saran, S., Saso, L., Parmar, V.S., Saxena, R.K., (2010), Optimization of lipase production from Aspergillus terreus by response surface methodology and its potential for synthesis of partial glycerides under solvent free conditions, Indian journal of microbiology, 50(4), 456-462 https://doi.org/10.1007/s12088-011-0100-y.

[22] Sin, J.C., Lam, S.M., Mohamed, A.R., (2011), Optimizing photocatalytic degradation of phenol by $\mathrm{TiO}_{2} / \mathrm{GAC}$ using response surface methodology, Korean Journal of Chemical Engineering, 28(1), 84 92 https://doi.org/10.1007/s11814-010-0318-0.

[23] Mohammad, Y.S., Shaibu-Imodagbe, E.M., Igboro, S.B., Giwa, A. Okuofu, C.A. (2014), Modeling and optimization for production of rice husk activated carbon and adsorption of phenol, Journal of Engineering, 278075

[24] Pei, J., Zhang, J.S., (2012), Determination of adsorption isotherm and diffusion coefficient of toluene on activated carbon at low concentrations, Building and Environment, 48, 66-76 https://doi.org/10.1016/j.buildenv.2011.08.005

[25] Li, Y., Du, Q., Liu, T., Peng, X., Wang J., Sun, J., Wang, Y., Wu, S. Wang, Z., Xia, Y., Xia, L. (2013), Comparative study of methylene blue dye adsorption onto activated carbon, graphene oxide, and carbon nanotubes, Chemical Engineering Research and Design, 91(2), 361-368 https://doi.org/10.1016/j.cherd.2012.07.007.

[26] Arellano-Cárdenas, S., Gallardo-Velázquez, T., Osorio-Revilla, G. López-Cortéz, M., Gómez-Perea, B. (2005), Adsorption of phenol and dichlorophenols from aqueous solutions by porous clay heterostructure (PCH), Journal of the Mexican Chemical Society, 49(3), 287-291.

[27] Huang, L., Sun, Y., Yang, T., Li, L. (2011), Adsorption behavior of $\mathrm{Ni}$ (II) on lotus stalks derived active carbon by phosphoric acid activation,Desalination, 268(1-3), 12-19Ren, L., Zhang, J., Li, https://doi.org/10.1016/j.desal.2010.09.044

[28] Ren, L., Zhang, J., Li, Y., Zhang, C. (2011), Preparation and evaluation of cattail fiber-based activated carbon for 2, 4-dichlorophenol and 2, 4, 6-trichlorophenol removal, Chemical engineering journal, $168(2), 553-561$

[29] Gupta, S.S., Bhattacharyya, K.G. (2011), Kinetics of adsorption of metal ions on inorganic materials: A review, Advances in Colloid and Interface Science, 162, 39-58

[30] Febrianto, J., Kosasih, A.N., Sunarso, J., Ju, Y., Indraswati, N., Ismadji, S. (2009), Equilibrium and kinetic studies in adsorption of heavy metals using biosorbent: A summary of recent studies, Journa of Hazardous Materials, 162, 616-645

[31] Oke, I.A., Olarinoye, N.O., Adewusi, S.R.A. (2008), Adsorption kinetics for arsenic removal from aqueous solutions by untreated powdered eggshell, Adsorption, 14(1), 73-83

[32] Tseng, R.L., Wu, F.C., Juang, R.S. (2003), Liquid-phase adsorption of dyes and phenols using pinewood-based activated carbons, Carbon, 41(3), 487-495,

[33] Srihari, V., Ashutosh, D. (2009), Adsorption of phenol from aqueous media by an agro-waste (Hemidesmus indicus) based activated cabon, Applied Ecology and Environmental Research, 7(1), 13-23
[34] Doke, K.M., Khan, E.M. (2017), Equilibrium, kinetic and diffusion mechanism of $\mathrm{Cr}$ (VI) adsorption onto activated carbon derived from wood apple shell, Arabian Journal of Chemistry, 10, S252-S260 